\title{
Quantification and prediction of the impact of fishing on epifaunal communities
}

\author{
G. I. Lambert ${ }^{1, *}$, S. Jennings ${ }^{2,3}$, M. J. Kaiser ${ }^{1}$, H. Hinz ${ }^{1}$, J. G. Hiddink ${ }^{1}$ \\ ${ }^{1}$ School of Ocean Sciences, Bangor University, Menai Bridge, Anglesey, LL59 5AB, UK \\ ${ }^{2}$ Centre for Environment, Fisheries and Aquaculture Science (CEFAS), Lowestoft Laboratory, Pakefield Road, Lowestoft, \\ Suffolk, NR33 0HT, UK \\ ${ }^{3}$ School of Environmental Sciences, University of East Anglia, Norwich, NR4 7TJ, UK
}

\begin{abstract}
The loss of emergent epifaunal biomass due to fishing impacts has not been quantified at the scale of an entire fishery. Here, based on an analysis of the impacts of the scallop dredge fleet around the Isle of Man, Irish Sea, we show how fishing and the physical environment act to determine the biomass and size composition of emergent epifauna. The epifauna create habitat structure that is used by juvenile scallops and other species, thus providing an important ecosystem service. Epifauna were identified and quantified based on photographs taken during an extensive survey of the territorial waters of the Isle of Man. On hard substrata, the effect of tidal velocity on total biomass $\left(\mathrm{g} \mathrm{m}^{-2}\right)$ and the maximum size $(\mathrm{g})$ of the largest organism encountered in each taxon was positive while wave stress and fishing frequency had a negative impact. We used the results to predict the distribution of biomass and maximum size and to quantify the total effects of fishing. Fishing frequency was the most important factor that affected maximum size of the epifauna, resulting in a mean decrease in size of $17 \%$ (range 0 to $66 \%$ ). Total biomass was predominantly affected by wave stress and tidal velocity while fishing caused a mean biomass decrease of $8 \%$ (range 0 to $34 \%$ ), equivalent to $1.8 \mathrm{~g}$ wet weight $\mathrm{m}^{-2}$. The results have implications for management because they provide an assessment of the overall impact of fishing at the scale of an entire fleet and inform the identification of areas where seabed habitats are most vulnerable to fishing.
\end{abstract}

KEY WORDS: Sessile benthos · Fishing impact · Environmental impact · Photographic survey

\section{INTRODUCTION}

Developing an ecosystem approach to fisheries (EAF) is regarded a necessary step towards achieving the sustainable use of marine resources (FAO 2003, Sinclair \& Valdimarsson 2003). In part, EAF requires that managers take account of fishing impacts, including those on seabed habitats. Bottom fishing, with towed gears such as beam trawls and scallop dredges, has direct (extraction of biomass, physical disturbance) and indirect effects (e.g. modification of trophic interactions) on benthic habitats (Kaiser et al. 2002). The majority of fishing impact studies have focused on communities found in soft sediment and gravel habitats (Collie et al. 2000, Kaiser et al. 2006a).

Emergent epifaunal species are here defined as all sessile or semi-sessile organisms that settle on hard surfaces or organisms with part of the body structure emerging from sediments. The growth forms, from encrusting to upright, create different levels of structural complexity and provide a source of food and/or shelter for other species. Epifauna are vulnerable to bottom fishing impacts and encrusting rather than upright emergent species dominate in fished areas (Collie et al. 1997, Bradshaw et al. 2001). Reductions in the abundance of emergent species are expected to lead to decreases in the range of ecological niches available for associated fauna (Gili \& Hughes 1995, Collie et al. 1997, Bradshaw et al. 2003). Many emergent sessile species are associated with a microcommunity of epifauna, e.g. caprellid amphipods on hydroids, or the fauna associated with pomatocerid tube worm heads (Kaiser et al. 1999). However, the response of emergent species to fishing has proved dif- 
ficult to quantify in a systematic way owing to the difficulty of sampling fauna attached to hard substrata, variation in life-history traits (colonial versus single individuals, senescence of some hydroids in winter), variation in body form with environmental conditions and the absence of precise estimates of the frequency and intensity of fishing impacts (Van Dolah et al. 1987, Henry et al. 2006).

Sessile epifaunal species and other habitat-forming organisms are widely distributed on the continental shelf and display a range of life-history traits and morphological characteristics that influence the environments where they are found and their vulnerability to fishing impacts. There is limited information on growth, reproduction, mortality and the ecological requirements of the sessile species that occur in northern European waters (see BIOTIC database, MarLIN website, www.marlin.ac.uk/biotic/). The distribution of these biota is affected by substratum stability, turbidity, nutrient supply, light availability, temperature and hydrodynamical conditions that in turn affect the resilience of the habitat to fishing disturbance (Hall 1994, Jennings et al. 1999, Callaway et al. 2002). A better understanding of the relationships between fishing, structure and size of epifaunal species and their environment is a requirement for EAF, since it can inform debates about the extent to which impacts compromise management objectives, the consequences of alternate management options and the effects of interaction between fisheries and the environment (Hiddink et al. 2007).

Here, we assess the relationships between the biomass of sessile epifauna, fishing intensity and the environment to better understand the effects of fishing on benthic habitat forming epifauna. The main focus of the present study is to quantify the impact of fishing on sessile fauna that live on hard substrata. Research was conducted in the territorial sea surrounding the Isle of Man, UK, where the scallop dredge fishery and the management restrictions applied to that fishery create gradients of fishing impacts on hard substrata. The seabed surrounding the Isle of Man has been fished by scallop dredgers for the last 60 years (Bradshaw et al. 2001). The availability of high-resolution fishing effort data for these fisheries permitted a reliable quantification of fishing impacts on sessile species across an environmental gradient.

\section{MATERIALS AND METHODS}

Data collection. Survey design: One hundred and twenty stations were sampled within the 12 nautical mile territorial limit of the Isle of Man in August 2008 (Fig. 1). The stations were located on a regular grid

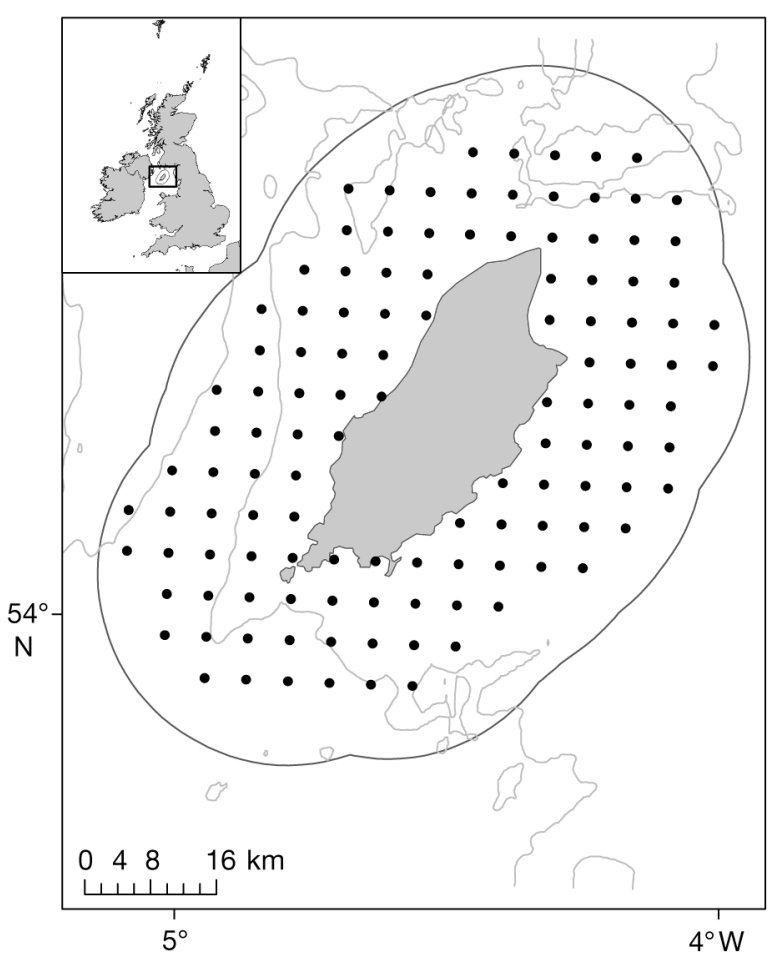

Fig. 1. Location of the 120 stations surveyed within 12 nautical miles of the Isle of Man. Light grey lines are $50 \mathrm{~m}$ bathymetric depth

with $5 \mathrm{~km}$ spacing to provide a comprehensive coverage of the seabed features around the island. Photographs of the seabed habitat were taken with a high resolution Canon 400D digital camera installed in an underwater housing and fitted to a sledge such that the objective lens pointed perpendicularly towards the seabed from a height of $60 \mathrm{~cm}$ above the seabed. The sledge was towed for $15 \mathrm{~min}$ at each station at a speed of 0.5 to 0.7 knots, covering an average distance of about $300 \mathrm{~m}$, as calculated from the starting and ending positions of each tow. Every $9 \mathrm{~s}$, a 10 megapixel photograph was taken (ca. 100 pictures per station); each photograph recorded an area of $0.3 \mathrm{~m}^{2}$. At each station, prior to the sledge tow, a $0.1 \mathrm{~m}^{2}$ Day grab was used to sample the sediment and a continuous CTD profile (depth, salinity and temperature) was recorded while the water column density was recorded every metre.

Still photographs analysis: Quantification of the habitat forming epifauna was based on a detailed analysis of the still photographs. Since such analyses are very time consuming, 10 still photographs from each selected station (ca. every 10th picture) were analysed using the grid and area measurement functions of ImageJ v.1.43 (National Institute of Mental Health). All the benthic habitat-forming organisms on the photographs were identified to the lowest possible 
taxonomic level. Identified species were from the Phyla Porifera, Cnidaria, Bryozoa and Chordata (Class Ascidiacea) and Mollusca (Class Bivalvia) and Arthropoda (Family Balanidae). Hereafter, the different groups are referred to as sponges, cnidarians, bryozoans, tunicates, bivalves and barnacles respectively. Despite the high quality of the images, identification and quantification of the sessile epifauna presented some significant challenges. First, some encrusting species were identified that could not be reliably related to any taxonomical group. Second, epifaunal Annelida could not be quantified as it was impossible to distinguish between live and dead specimens as live tubeworms are usually retracted in their tubes. Third, the taxonomy of many organisms could not be resolved below the level of phylum, as most organisms necessitate microscopic study to identify distinguishing features. Species were, therefore, mostly grouped into phyla, although cnidarians were split into the classes: Hydrozoa (hydroids) and Anthozoa (dead man's fingers and anemones). In addition to the taxonomic groupings, analyses were based on 2 major functional traits: (1) body plan, colonial versus solitary, and (2) body shape, 2-dimensional encrusting versus hard calcified species such as bivalves and barnacles versus flexible organisms such as emergent cnidarians, bryozoans, tunicates and sponges (see Tables S1 \& S2 in the supplement at www.int-res.com/articles/suppl/ m430p071_supp.pdf for details on the dominant species).

To quantify the coverage of each taxon, a grid of 96 intersection points was superimposed onto each photograph and the number of intersection points covered by each taxon recorded. Each point represented 1/96, i.e. $1.04 \%$ of the total coverage.

Biomass estimation of habitat forming species: Although coverage describes one aspect of community structure, biomass is also a relevant metric when assessing the effects of human impacts, because size distributions of individuals as well as their frequency of occurrence can be modified. Consequently, we analysed 2-dimensional encrusting species in terms of coverage but we estimated the biomass for emergent species. To enable us to estimate biomass from the images, upright sessile organisms, collected with a scallop dredge off the Isle of Man in October 2009, were used to determine relationships between the area of organisms (in the pictures) and mass. Each organism was weighed to $\pm 0.001 \mathrm{~g}$ and then pinned to a flat wooden panel on the bottom of a deep tank filled with seawater, before being photographed with the same equipment and same camera position used during the photographic survey. The area covered by each organism was calculated with ImageJ. Organisms were classified into those that could be treated as 2-dimensional (hydroids, mound shape sponges and bryozoans such as Flustra foliacea and Cellaria sinuosa) and those to be treated as 3-dimensional (ascidians, anthozoans and erect sponges). The equations linking area of coverage to mass are given in Table S3 in the supplement at www.int-res.com/articles/suppl/m430p071_ supp.pdf.

On the survey photographs, the area covered by each taxon recorded under the intersection points was measured with ImageJ. Before applying the areamass equations to estimate biomass from the survey photographs, it was necessary to correct for the orientation of the organism in relation to the seabed, which varied in response to current speed. A subsample of 18 organisms was used to link the area covered by an organism lying on the seabed to the area covered by this same organism tilted at 20,45 or 80 degrees from the seabed. The correction factors obtained were respectively 1.09, 1.24 and 1.91 . On the survey photographs, the angle of exposure was estimated visually, along with the number of layers when the species formed a multilayer clump. An estimation of the flat area covered by each recorded organism was then obtained by multiplying the covered area by its correction factor and by the number of layers. The corrected mass was then determined by applying the area-mass equations to the corrected area for each organism (Table S3). All biomass data were fourth-root transformed prior to statistical analyses to reduce heteroscedasticity in the data. The maximum size reached by any organism within each group (in g) and total biomass of the whole community (in $\mathrm{g} \mathrm{cm}^{-2}$ ) per station were reported. Total biomass was the sum of individual mass measurements.

Fishing effort data: Fishing effort data for king and queen scallop dredging vessels were obtained from the European Community Satellite Vessel Monitoring System (VMS). UK and Isle of Man VMS data within $12 \mathrm{n}$ miles of the Isle of Man coast were provided by the Isle of Man Ministry of Fisheries. Because the information for the Isle of Man fleet came from fishermen's log-books and because all the UK vessels in these waters were above $15 \mathrm{~m}$ and fitted with VMS transceivers, we achieved $100 \%$ coverage of fishing vessel activity for the period 2007 to 2008. In the absence of pre-2007 data, we assumed that the distribution of the effort was consistent among years because fishers were most likely to repeatedly return to locations that they knew from past experience (Kaiser 2005). The VMS data do not indicate whether a vessel is fishing when its position is recorded but its speed can be used as an indication of its activity. The data obtained by the Department of Agriculture, Fisheries \& Food were filtered on the assumption that speeds between 1.2 and 3.2 knots indicated fishing activity as scallop fishing 
gear as used in waters around the Isle of Man is most effective when fished within this range of towing speeds (Jenkins et al. 2001). We defined fishing intensity as the number of times an area of $1 \mathrm{~km}^{2}$ was swept by fishing gears in $1 \mathrm{yr}$. A fishing frequency of $1 \mathrm{yr}^{-1}$ means that the $1 \mathrm{~km}^{2}$ area has been swept once on average during a 1 yr period. Each VMS record was assumed to represent $2 \mathrm{~h}$ of fishing as this is the recording interval. The area dredged by each vessel per unit time was calculated as the product of fishing speed and gear width. Fishing speed was calculated as the average fishing speed per vessel based on all VMS records for that vessel. To calculate gear width, vessels fishing within $3 \mathrm{n}$ miles were assumed to use 10 dredges (each with a width of $0.76 \mathrm{~m}$ ), while vessels fishing between 3 and $12 \mathrm{n}$ miles were assumed to carry 16 dredges; the maximum numbers of dredges allowed in each of these fishing zones respectively. The sum of the area dredged in each $1 \mathrm{~km}^{2}$ cell was calculated with ArcGIS 9.3, giving the actual fishing frequency. Fishing frequency ranged from 0 to $2.8 \mathrm{yr}^{-1}$, similar to the range of fishing intensities estimated for other areas in European shelf seas (Jennings et al. 2001, Hiddink et al. 2006).

Environmental data: The depth at the sampled stations ranged from 6 to $100 \mathrm{~m}$. Salinity and temperature measurements were excluded from further analyses because the measured ranges were narrow and not expected to have a differential effect on the species of interest within the survey area. This is because the species of interest were euryhaline (able to tolerate a wide range of salinities) whereas the recorded range of bottom salinity was narrow (32.9 to $34.2 \%$ ). Similarly, the average sea surface temperature range was narrow $\left(14.0\right.$ to $\left.15.5^{\circ} \mathrm{C}\right)$. The bottom temperature range was slightly wider $\left(12.6\right.$ to $\left.15.8^{\circ} \mathrm{C}\right)$ but still represented only a snapshot in time that was unlikely to influence epifaunal distributions. The extent of stratification did vary among stations and an index of stratification, the potential energy (PE) anomaly (PEA), was calculated from the density profiles. PEA is the difference between the actual PE of the water column and the PE of the same water column after being vertically mixed (Eq. 1). The higher the PEA value, the more stratified the water column. PEA was calculated as:

$$
\operatorname{PEA}\left(\mathrm{J} \mathrm{m}^{-3}\right)=\frac{1}{h} \sum_{z} g z(\bar{\rho}-\rho) \Delta z
$$

where $h=$ total depth of the water column (m), $g=9.81$ $\mathrm{m} \mathrm{s}^{-2}, \bar{\rho}=$ density of one block of water in the water column $\left(1\right.$ block $\left.\mathrm{m}^{-1}\right), \rho=$ density of the vertically mixed water column, $z=$ depth of the block of water (m) (Simpson et al. 1982).

A sample of $50 \mathrm{~cm}^{3}$ of the surface sediment in the grab sample was removed for particle size analysis.
Samples were stored in the dark at $3^{\circ} \mathrm{C}$. Laboratory analysis followed standard methods (Eleftheriou \& Moore 2005). The percentage of mud in the sediment was considered as a factor that could affect epifaunal distributions as it is a surrogate for substratum stability. An unstable substratum might not be suitable for the development of sessile organisms. As the presence of coarse substratum precluded some grab collections, substratum type was qualitatively identified from the still images: mud (Mu), sand (S), sand-shell (SS), maerl (Ma), mixed gravel (MG) and hard $\left(\mathrm{H}_{\text {; }}\right.$ including cobbles and rocks). We also considered the percentage of living bivalves as an environmental parameter since many other species appeared to settle on their shells regardless of the dominant substratum type at the station.

Estimates of wave-induced bed shear stress and tidal velocity at the study sites were obtained from a model developed for the Irish Sea (see detailed description in Hiddink et al. 2009). The wave stress is a measure of the orbital velocity $\left(\mathrm{m} \mathrm{s}^{-2}\right)$ due to waves at the seabed and the tidal velocity is the peak speed $\left(\mathrm{m} \mathrm{s}^{-1}\right)$ of the depth-mean current at the time of mean tides (i.e. midway between spring and neap tides).

Long term data series of chlorophyll a ( $\mathrm{chl}$ a) and turbidity were downloaded from NEODAAS (NERC Earth Observation Data Acquisition and Analysis Service, www.neodaas.ac.uk). Surface chl a and turbidity averages (where $K_{490}$ is the diffuse attenuation coefficient at $490 \mathrm{~nm}$ ) were obtained from the MODIS sensor (1 $\mathrm{km}$ scale resolution). The data provided were monthly averages for the period 2002 to 2007. They were provided as GeoTIFF files, in digital numbers (DN). Mean summer chl $a$ and turbidity per $1 \mathrm{~km}^{2}$ cell was calculated for the whole period with ArcGIS 9.3. We adopted this approach because the overall productivity and biomass in the food web will depend on time-integrated production rather than instantaneous rates. Data were extracted for each station and, based on the recommendations given by the data provider, the following equations were applied:

$$
\begin{aligned}
& \text { MODIS chl a }\left(\mathrm{mg} \mathrm{m}^{-3}\right)=10^{[(\mathrm{DN} \times 0.015)-2]} \\
& \text { MODIS turbidity } K_{490}\left(\mathrm{~m}^{-1}\right)=10^{[(\mathrm{DN} \times 0.011176)-2]}
\end{aligned}
$$

The wave stress and percentage of living bivalve data were corrected by logarithmic transformation to achieve homogeneity.

Data analysis. Identification of the responses of habitat-forming species: To identify the environmental factors that affect the coverage of encrusting species and the maximum size and total biomass of emergent ones, we used univariate quantile regressions (Koenker \& Bassett 1978, Cade \& Noon 2003). Quantile regressions are linear models that allow the response 
data to be split into quantile classes. The function fits a model by minimizing a weighted sum of absolute residuals (see Cade et al. 1999 for further details on the method). For instance, the 95th quantile describes the function in which $95 \%$ of the observations are under the fitted line. Such a quantile can be used to examine how the biomass of the fauna is limited by a factor, regardless of the presence of other limiting factors (Blackburn et al. 1992, Cade \& Noon 2003). The 75th, 80th, 85th, 90th and 95th quantiles of epifaunal coverage and biomasses measurements of different functional and taxonomic groups were tested in relation to fishing frequency and to each environmental variable to determine which parameters were inducing a response of the epifauna and at which quantile levels they showed an effect. The choice of these 5 quantiles was adapted from an approach used to detect species responses (Vaz et al. 2008). The use of different quantiles did not impair the interpretation of the results as the regressions were only used to detect potential limiting factors rather than to compare responses among variables. Although looking at 5 different quantiles led to over-estimates of the number of significant responses, the use of the quantiles was necessary to identify all the potential limiting factors to include in the final multi-linear models.

Linear rather than non-linear quantile regression models were used because the fit of non-linear models often depends on the starting values given as inputs. A strong statistical test would then be required to test for the goodness-of-fit, as no such test exists for non-linear quantile regressions so far as we are aware. First and second order polynomial linear quantile regressions of epifaunal biological data on fishing frequency and environmental parameters, both raw and log-transformed (except for the initially log-transformed wave stress and percentage of living bivalves data), were statistically tested to identify the shape of the responses. The standard errors, on which the goodness of the fit was estimated, were calculated using a standard bootstrapping method implemented in R ( $\mathrm{R}$ Development Core Team 2008, www.r-project.org). The highest significant quantile was kept for each significant model within each species group. In each species group, the significant models were then compared by using the Akaike's Information Criterion (AIC) (Venables \& Ripley 2002). The model with the lowest AIC was selected. We could consequently summarise, for each species groups, which external factors were likely to affect their maximum size and total biomass and the shape of the response.

Univariate quantile regressions could only be applied to numerical variables. Therefore, the effect of substratum type on epifauna was studied separately by ANOVA. The individual effects of the different sub- stratum types were analysed with a multiple comparison post hoc Tukey's HSD test.

Spatial autocorrelations: The existence of spatial autocorrelations in the biomass data would affect the significance of the relationships between species distribution and external factors as identified from the analyses described above. The Moran's I and Geary's $C$ weighted spatial autocorrelation indices are generally used to check for such autocorrelations (Jumars et al. 1977, Kendall et al. 2005, Kraan et al. 2009). The Moran's $I$ test detects global autocorrelations within the whole study area while the Geary's $C$ test is more sensitive to local autocorrelation in close neighbourhoods.

The weights are inversely proportional to distance ${ }^{2}$ between stations. However, because the sampling area surrounded the Isle of Man, the distance between eastern and western stations was interrupted by the land mass and hence was not informative about spatial autocorrelation. The near-surface currents flow from the south to the north of the island on both the western and eastern coasts, which divided the sampling area in terms of ecological connectivity. The spatial autocorrelation analyses were thus conducted separately within the western stations and within the eastern stations. The tests were performed at the species group level, i.e. bivalves, barnacles, hydrozoans, anthozoans, bryozoans, sponges and tunicates.

Identification of the drivers and prediction of epifaunal development: The explanatory variables, or factors, showing a consistent and significant effect across all or most functional and taxonomical groups, as identified from the univariate quantile regression analysis, were retained for further analyses. The objective was to assess the relative contribution of these factors to the development of habitat-forming communities in hard bottom areas. Most classical multivariate analyses techniques cannot be used because explanatory variables are noisy, partially redundant or co-linear (Cushman et al. 2008). We checked for colinearity of potential explanatory variables by calculating the Spearman's rank correlation coefficient for each pair of parameters. We found that most factors were significantly correlated (Table 1). Depth was directly excluded as a potential explanatory factor because it could only impact the epifauna indirectly through its correlation to the other environmental gradients. Stratification was highly correlated with depth (correlation coefficient $=0.86, \mathrm{p}<0.001$ ) and other factors so this was also excluded. Since we could not make measurements of mud content at the hard bottom stations, the percentage of mud was also excluded from the multivariate analyses. We used partial least squares (PLS) regressions for our multivariate analyses, with the PLS package in R (Mevik \& 
Table 1. Pearson correlation coefficients for all combinations of environmental variables and fishing frequency. PEA: potential energy anomaly. Significance levels: ${ }^{* * *} \mathrm{p}<0.001,{ }^{* *} \mathrm{p}<0.01,{ }^{*} \mathrm{p}<0.05,{ }^{\circ} \mathrm{p}<0.1$

\begin{tabular}{|c|c|c|c|c|c|c|c|c|c|}
\hline & $\begin{array}{l}\text { Depth } \\
\text { (m) }\end{array}$ & $\begin{array}{c}\text { PEA } \\
\left(\mathrm{J} \mathrm{m}^{-3}\right)\end{array}$ & $\begin{array}{c}\mathrm{Chl} \mathrm{a} \\
\left(\mathrm{mg} \mathrm{m}^{-3}\right)\end{array}$ & $\begin{array}{l}\text { Tidal velocity } \\
\qquad\left(\mathrm{m} \mathrm{s}^{-1}\right)\end{array}$ & $\begin{array}{c}\text { Turbidity } \\
\left(\mathrm{m}^{-1}\right)\end{array}$ & $\begin{array}{l}\text { Mud } \\
(\%)\end{array}$ & $\begin{array}{l}\text { Wave stress } \\
\quad\left(\mathrm{m} \mathrm{s}^{-2}\right)\end{array}$ & $\begin{array}{l}\text { Bivalves } \\
\text { (\% cover) }\end{array}$ & $\begin{array}{c}\text { Fishing freq } \\
\left(\mathrm{yr}^{-1}\right)\end{array}$ \\
\hline Depth & 1 & $0.86^{* * *}$ & $-0.43^{* * *}$ & $0.25^{*}$ & $-0.65^{* * *}$ & $0.48^{* * *}$ & $-0.66^{* * *}$ & -0.11 & -0.1 \\
\hline PEA & & 1 & $-0.34^{* * *}$ & 0.04 & $-0.69^{* * *}$ & $0.60^{* * *}$ & $-0.53^{* * *}$ & 0 & 0.01 \\
\hline Chl a & & & 1 & -0.12 & $0.72^{* * *}$ & $-0.18^{\bullet}$ & $0.08^{\bullet}$ & 0.16 & $-0.17^{\bullet}$ \\
\hline Tidal velocity & & & & 1 & 0.12 & $-0.37^{* * *}$ & $-0.41^{* *}$ & $-0.18^{\circ}$ & $-0.18^{\bullet}$ \\
\hline Turbidity & & & & & 1 & $-0.51^{* * *}$ & $0.26^{* * *}$ & 0.02 & $-0.17^{\circ}$ \\
\hline Mud & & & & & & 1 & $-0.25^{* * *}$ & 0.17 & 0.13 \\
\hline Wave stress & & & & & & & 1 & 0.05 & 0.07 \\
\hline Bivalves & & & & & & & & 1 & -0.03 \\
\hline Fishing freq. & & & & & & & & & 1 \\
\hline
\end{tabular}

Wehrens 2007). PLS has only recently been applied to terrestrial and freshwater ecology studies (Zhang et al. 2009, Rossi \& van Halder 2010) while it has been widely used in other scientific fields, especially in chemometrics; the science of extracting information from chemical systems by data-driven means (Wold et al. 2001). PLS regressions have been developed to deal with cases where there are many explanatory variables in relation to the number of observations and/or with cases of severe multicollinearity (Carrascal et al. 2009). A PLS regression is a linear regression of one or more response variables onto a number of components called latent variables. The latent variables are linear combinations of the factors, also called predictor variables. They are constructed so that the original multi-collinearity is reduced to a lower number of orthogonal factors. PLS regression differs from principal component analysis (PCA) because PLS regression maximises the covariance between the scores and the response (Mevik \& Wehrens 2007, Rossi \& van Halder 2010) while PCA maximises variance of the scores. The variance explained and the root mean squared error of prediction (RMSEP) were used to determine the number of relevant components. The variable importance in projection (VIP) approach (Chong \& Jun 2005) was used to order the pertinent original explanatory variables by rank importance. To determine the final model we selected the explanatory variables with VIP values greater than 1; the standard criterion for factor selection (Chong \& Jun 2005). We calculated the coefficients of the linear regression between predicted response values and observations and we extracted the regression coefficients of the significant factors in the PLS regression to estimate the final model and test the goodness of the fit. The computations were done in $\mathrm{R}$ with the function VIP.R (available online at http://mevik.net/work/software/VIP.R). All continuous factors were log-transformed to correct for heteroscedasticity.

\section{RESULTS}

\section{Impact of scallop dredging on benthic epifauna}

The maximum size and total biomass of the emergent habitat-forming organisms were significantly limited by fishing frequency (Fig. 2, Table 2), but there was no relationship between fishing frequency and the coverage of encrusting species (Table 2). At the functional level, solitary, colonial and flexible groups were negatively affected (i.e. exhibited significantly decreasing responses), and hard-body species appeared to be positively affected (i.e. exhibiting significantly increasing responses). Analyses at the taxonomic level revealed some differences among taxa. The biomass and maximum sizes of Cnidaria were negatively related to fishing frequency, although for the maximum size of Anthozoa this was not a significant relationship (Fig. 2, Table 2). The relationships between maximum size and total biomass of Balanidae, Bryozoa and Ascidiacea with fishing frequency were not significant (Fig. 2). Porifera and Bivalvia responded positively to increasing fishing frequency. There were few data for Bivalvia and Balanidae and consequently for the overall hard body functional group and these data were unlikely to represent the response of these groups to fishing disturbance. The survey design and the image analysis method were not well adapted to biomass estimation for small species such as barnacles or to motile, gregarious and/or semi-buried bivalves. Indeed, bivalves recorded in the images were primarily free-swimming queen scallops; only half of the images at one of the stations covered a Modiolus bed, while king scallops were only recorded in the images from 2 stations.

\section{Epifaunal responses to environmental variables}

ANOVA revealed that the coverage of encrusting species, as well as the maximum size and total biomass 


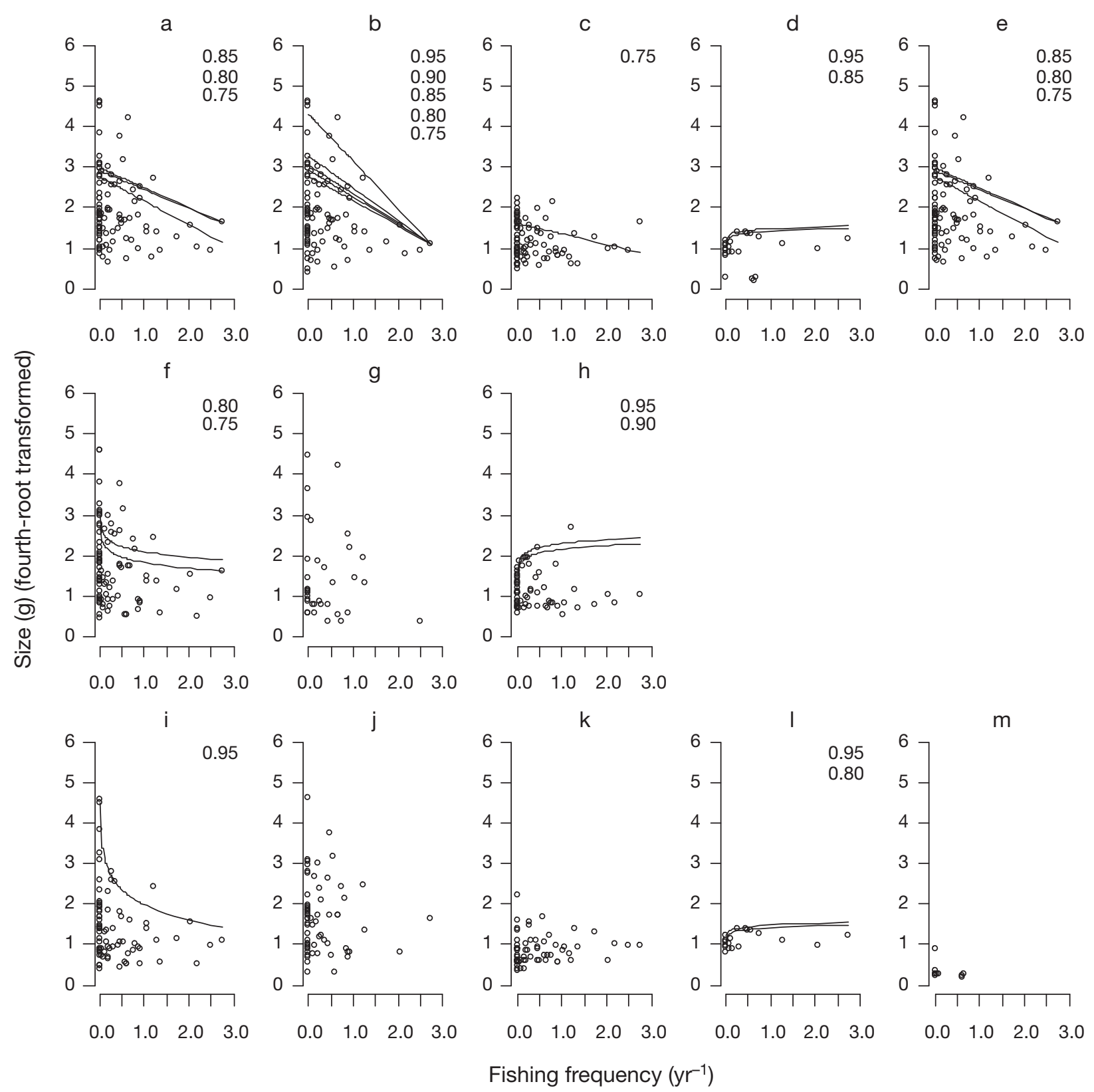

Fig. 2. Relationship between maximum size of the different species groups and fishing frequency. Size is the fourth-root transformed maximum biomass observed at each station. Black lines are the significant quantile regressions. Significant quantiles are listed in each panel. Equations and statistics of the highest significant quantiles are given in Table 2. Functional groups: (a) emergent epifauna, (b) colonial species, (c) solitary species, (d) hard-body species, (e) flexible species. Phyla: (f) Cnidaria, (g) Bryozoa, (h) Porifera. Families: (i) Hydrozoa, (j) Anthozoa, (k) Ascidiacea, (l) Bivalvia, (m) Balanidae

of emergent biota, varied significantly with substratum type (Table 3, Fig. 3), such that fauna with the greatest maximum size and total biomass occurred on stable substrata, i.e. mixed gravel and hard bottom. In contrast, for hard-bodied non-sessile species there was no relationship between biomass and/or size and substratum type.

Univariate quantile regressions revealed that all functional and taxonomical groups, except for encrusting species, hard-bodied species and Porifera, fol- lowed similar significant patterns along the different environmental gradients. Maximum sizes and total biomass peaked or decreased with depth, increased with tidal velocity, peaked or decreased with stratification, increased with chl $a$, decreased with mud content of the sediment, increased with turbidity and decreased with wave stress (Fig. 3, Table 4, see Table S4 in the supplement at www.int-res.com/articles/suppl/ m430p071_supp.pdf for equations and statistics). Although the functional and species groups did not all 
Table 2. Results of the quantile regressions of the species biological measurements on fishing frequency: sign of the impact (positive + , negative -), slope estimates and probabilities. log indicates whether the factor was log-transformed (see 'Materials and methods: Data analysis'). No entry corresponds to no significant impact. See also Fig. 2

\begin{tabular}{|c|c|c|c|c|c|}
\hline Species group & Variable & Dredge impact & Slope & $\mathrm{p}$ & Quantile \\
\hline Encrusting & Coverage & & & & \\
\hline \multirow[t]{2}{*}{ Emergent } & Maximum size & - & -0.492 & 0.010 & 85 \\
\hline & Total biomass & - & -0.805 & 0.013 & 80 \\
\hline \multirow[t]{2}{*}{ Colonial } & Maximum size & - & -1.172 & 0.047 & 95 \\
\hline & Total biomass & - & -0.768 & 0.021 & 80 \\
\hline \multirow[t]{2}{*}{ Solitary } & Maximum size & $-\log$ & -0.098 & 0.030 & 80 \\
\hline & Total biomass & $-\log$ & -0.117 & $<0.001$ & 95 \\
\hline \multirow[t]{2}{*}{ Hard body } & Maximum size & $+\log$ & 0.059 & 0.017 & 95 \\
\hline & Total biomass & + & 0.657 & 0.040 & 80 \\
\hline \multirow[t]{2}{*}{ Bivalvia } & Maximum size & $+\log$ & 0.060 & 0.032 & 95 \\
\hline & Total biomass & + & 0.657 & 0.043 & 80 \\
\hline \multirow[t]{2}{*}{ Balanidae } & Maximum size & & & & \\
\hline & Total biomass & & & & \\
\hline \multirow[t]{2}{*}{ Flexible } & Maximum size & - & -0.492 & 0.011 & 85 \\
\hline & Total biomass & - & -0.482 & 0.017 & 85 \\
\hline \multirow[t]{2}{*}{ Cnidaria } & Maximum size & $-\log$ & -0.191 & 0.034 & 80 \\
\hline & Total biomass & - & -0.597 & 0.036 & 90 \\
\hline \multirow[t]{2}{*}{ Hydrozoa } & Maximum size & $-\log$ & -0.543 & 0.002 & 95 \\
\hline & Total biomass & $-\log$ & -0.454 & 0.012 & 95 \\
\hline \multirow[t]{2}{*}{ Anthozoa } & Maximum size & & & & \\
\hline & Total biomass & - & -0.592 & 0.031 & 90 \\
\hline \multirow[t]{2}{*}{ Bryozoa } & Maximum size & & & & \\
\hline & Total biomass & & & & \\
\hline \multirow[t]{2}{*}{ Porifera } & Maximum size & $+\log$ & 0.146 & 0.025 & 95 \\
\hline & Total biomass & $+\log$ & 0.254 & 0.024 & 95 \\
\hline \multirow[t]{2}{*}{ Ascidiacea } & Maximum size & & & & \\
\hline & Total biomass & & & & \\
\hline
\end{tabular}

respond significantly to all the environmental factors (Table 4), the similarity of the responses did not justify the grouping of the emergent sessile epifauna at different functional or taxonomical levels. Within the group of emergent flexible species, only Porifera had a divergent response as the maximum size and total biomass appeared to decrease in the highest range of the tidal velocity gradient. The Porifera were also positively influenced by the percentage cover of bivalves. However, the responses of the Porifera group to the different variables were likely to be biased because of spatial autocorrelations (see later). The bivalve biomass estimates followed a different pattern as they increased with the mud content of the sediment. Encrusting species and barnacles did not show any response with any of the environmental gradients.

In summary, these results show that the biomass of only the emergent epifauna is largely related to the external factors considered in this study. Substratum category, fishing frequency, depth, stratification, tidal velocity, chl $a$, turbidity, mud in the sediment and wave stress were all potential drivers of the emergent epifauna.

\section{Spatial autocorrelations}

Sponge biomass was strongly spatially autocorrelated in both the western and eastern areas (Table 5). There was no other strong spatial autocorrelation within the eastern stations. The cnidarian species, Hydrozoa and Anthozoa, were only spatially autocorrelated in the western area, with a low Moran's I value. All other species groups did not show any strong pattern which suggested that, although not all species were independently distributed, the responses of the sponge biomass to external factors should be interpreted with caution.

\section{Identification of the factors driving epifaunal characteristics}

Based on the above results, to assess the impact of the different factors driving maximum size and biomass in a multivariate analysis, we conducted the analyses on the combined biomass of the emergent sessile epifauna, including hard-bodied species and Porifera. These data were combined because the biomass of the component groups of hard-bodied species and Porifera was low.

The responses of epifaunal biomass to depth, stratification and mud content of the sediment were not accounted for in the multivariate analyses (see 'Materials and methods: Data analysis'). Owing to the significant effect of substratum type, and because it was the only categorical variable, we modelled stable habitats separately from unstable habitats using the remaining 5 factors in the PLS regressions. For both maximum size and total biomass in stable habitats, 5 latent variables were identified, from which we kept the first 2 because the RMSEP decreased only slightly with an increasing number of components. The variability explained by these 2 components was $90 \%(52+38)$ for maximum size and $90 \%(45+45)$ for total biomass; and the responses were similar for both biological measurements. The VIP values indicated that fishing frequency was the most important factor, followed by tidal velocity and wave stress for maximum size. For total biomass, wave stress and tidal velocity preceded fishing frequency (Table 6). The VIP values of chl a and turbidity were less than 1 on both components and so discarded. A similar model could not be fitted to data for unstable mud or sand substrata as the RMSEP 
Table 3. ANOVA of the species biological measurements in relation to substratum type. Substratum types are mud (Mu), sand (S), sand-shell (SS), mixed gravel (MG) and hard (H). Significance levels: ${ }^{* *} p<0.001,{ }^{* *} p<0.01,{ }^{*} p<0.05$. Significant comparisons between substratum types are revealed by Tukey's HSD test

\begin{tabular}{|c|c|c|c|c|c|c|c|}
\hline \multirow{2}{*}{ Species group } & \multirow{2}{*}{ Variable } & \multirow[b]{2}{*}{$\mathrm{df}$} & \multicolumn{2}{|c|}{ ANOVA } & \multirow[b]{2}{*}{ Comparison } & \multirow{2}{*}{$\begin{array}{c}\text { Tukey's test } \\
\text { Diff. }\end{array}$} & \multirow[b]{2}{*}{$\mathrm{p}$} \\
\hline & & & $F$ & $\mathrm{p}$ & & & \\
\hline \multirow[t]{4}{*}{ Encrusting } & Coverage & 5 & 6.703 & $<0.001^{* * *}$ & $\mathrm{~S}-\mathrm{H}$ & -0.136 & 0.003 \\
\hline & & & & & $\mathrm{Mu}-\mathrm{H}$ & -0.145 & $<0.001$ \\
\hline & & & & & $\mathrm{Mu}-\mathrm{MG}$ & -0.105 & 0.006 \\
\hline & & & & & $\mathrm{Mu}-\mathrm{SS}$ & -0.102 & 0.027 \\
\hline \multirow[t]{7}{*}{ Emergent } & Maximum size & 5 & 4.379 & $0.001^{* *}$ & SS-H & -1.020 & 0.020 \\
\hline & & & & & $\mathrm{Mu}-\mathrm{H}$ & -1.000 & 0.007 \\
\hline & Total biomass & 5 & 11.197 & $<0.001^{* * *}$ & $\mathrm{SS}-\mathrm{H}$ & -1.509 & 0.009 \\
\hline & & & & & $\mathrm{S}-\mathrm{H}$ & -1.769 & 0.001 \\
\hline & & & & & $\mathrm{Mu}-\mathrm{H}$ & -2.204 & $<0.001$ \\
\hline & & & & & S-MG & -1.328 & 0.017 \\
\hline & & & & & $\mathrm{Mu}-\mathrm{MG}$ & -1.763 & $<0.001$ \\
\hline \multirow[t]{4}{*}{ Colonial } & Maximum size & 5 & 2.406 & $0.043^{*}$ & & & \\
\hline & Total biomass & 5 & 10.179 & $<0.001^{* * *}$ & $\mathrm{~S}-\mathrm{H}$ & -1.512 & 0.016 \\
\hline & & & & & $\mathrm{Mu}-\mathrm{H}$ & -2.249 & $<0.001$ \\
\hline & & & & & $\mathrm{Mu}-\mathrm{MG}$ & -1.891 & $<0.001$ \\
\hline \multirow[t]{11}{*}{ Solitary } & Maximum size & 5 & 8.780 & $<0.001^{* * *}$ & $\mathrm{SS}-\mathrm{H}$ & -0.688 & 0.001 \\
\hline & & & & & $\mathrm{S}-\mathrm{H}$ & -0.678 & 0.002 \\
\hline & & & & & $\mathrm{Mu}-\mathrm{H}$ & -0.722 & $<0.001$ \\
\hline & & & & & SS-MG & -0.531 & 0.016 \\
\hline & & & & & S-MG & -0.521 & 0.027 \\
\hline & & & & & Mu-MG & -0.565 & 0.002 \\
\hline & Total biomass & 5 & 10.595 & $<0.001^{* * *}$ & $\mathrm{SS}-\mathrm{H}$ & -1.030 & 0.002 \\
\hline & & & & & $\mathrm{S}-\mathrm{H}$ & -1.180 & $<0.001$ \\
\hline & & & & & $\mathrm{Mu}-\mathrm{H}$ & -1.306 & $<0.001$ \\
\hline & & & & & S-MG & -0.841 & 0.012 \\
\hline & & & & & $\mathrm{Mu}-\mathrm{MG}$ & -0.966 & $<0.001$ \\
\hline \multirow[t]{2}{*}{ Hard body } & Maximum size & 4 & 0.434 & 0.550 & & & \\
\hline & Total biomass & 5 & 2.500 & $0.035^{*}$ & & & \\
\hline \multirow[t]{2}{*}{ Bivalvia } & Maximum size & 4 & 1.005 & 0.437 & & & \\
\hline & Total biomass & 5 & 2.359 & $0.045^{*}$ & & & \\
\hline \multirow[t]{2}{*}{ Balanidae } & Maximum size & 4 & 0.932 & 0.513 & & & \\
\hline & Total biomass & 5 & 0.825 & 0.535 & & & \\
\hline \multirow[t]{7}{*}{${ }^{\mathrm{a}}$ Flexible } & Maximum size & 5 & 4.383 & $0.001^{* *}$ & $\mathrm{SS}-\mathrm{H}$ & -1.041 & 0.017 \\
\hline & & & & & $\mathrm{Mu}-\mathrm{H}$ & -1.000 & 0.007 \\
\hline & Total biomass & 5 & 10.915 & $<0.001^{* * *}$ & $\mathrm{SS}-\mathrm{H}$ & -1.521 & 0.009 \\
\hline & & & & & $\mathrm{S}-\mathrm{H}$ & -1.760 & 0.001 \\
\hline & & & & & $\mathrm{Mu}-\mathrm{H}$ & -2.200 & $<0.001$ \\
\hline & & & & & S-MG & -1.301 & 0.023 \\
\hline & & & & & $\mathrm{Mu}-\mathrm{MG}$ & -1.742 & $<0.001$ \\
\hline
\end{tabular}

values increased with the number of latent variables. This showed that no combination of the above factors could explain the variability of biomass.

In stable substratum areas, the linear regressions relating predicted and measured biomass were significant $\left(F=11.7, \mathrm{p}=0.001\right.$ and $\mathrm{r}^{2}=0.18$ for maximum size $F=8.8, \mathrm{p}=0.005, \mathrm{r}^{2}=0.14$ for total biomass). The equations were the following:

$$
\begin{aligned}
\sqrt[4]{W} & =0.956 \widehat{W}+2.163 \\
\sqrt[4]{B} & =0.960 \widehat{B}+2.201
\end{aligned}
$$

With $W$ and $B$ being the measured maximum size (g) and total biomass $\left(\mathrm{g} \mathrm{m}^{-2}\right)$, and $\widehat{W}$ and $\widehat{B}$ being the corresponding predicted values calculated from the following equations:

$$
\begin{aligned}
\widehat{W} & =0.231 V-0.068 F F \\
\widehat{B} & =0.217 V-0.180 S-0.027 F F
\end{aligned}
$$

with tidal velocity $(V)$ in $\mathrm{m} \mathrm{s}^{-1}$, wave stress $(S)$ in $\mathrm{m} \mathrm{s}^{-2}$ and fishing frequency $(F F)$ in $\mathrm{yr}^{-1}$. All were multiplied by 100 and increased by +1 before being log transformed.

Equations 6 and 7 were used to predict the distribution of the epifaunal biomass around the Isle of Man 

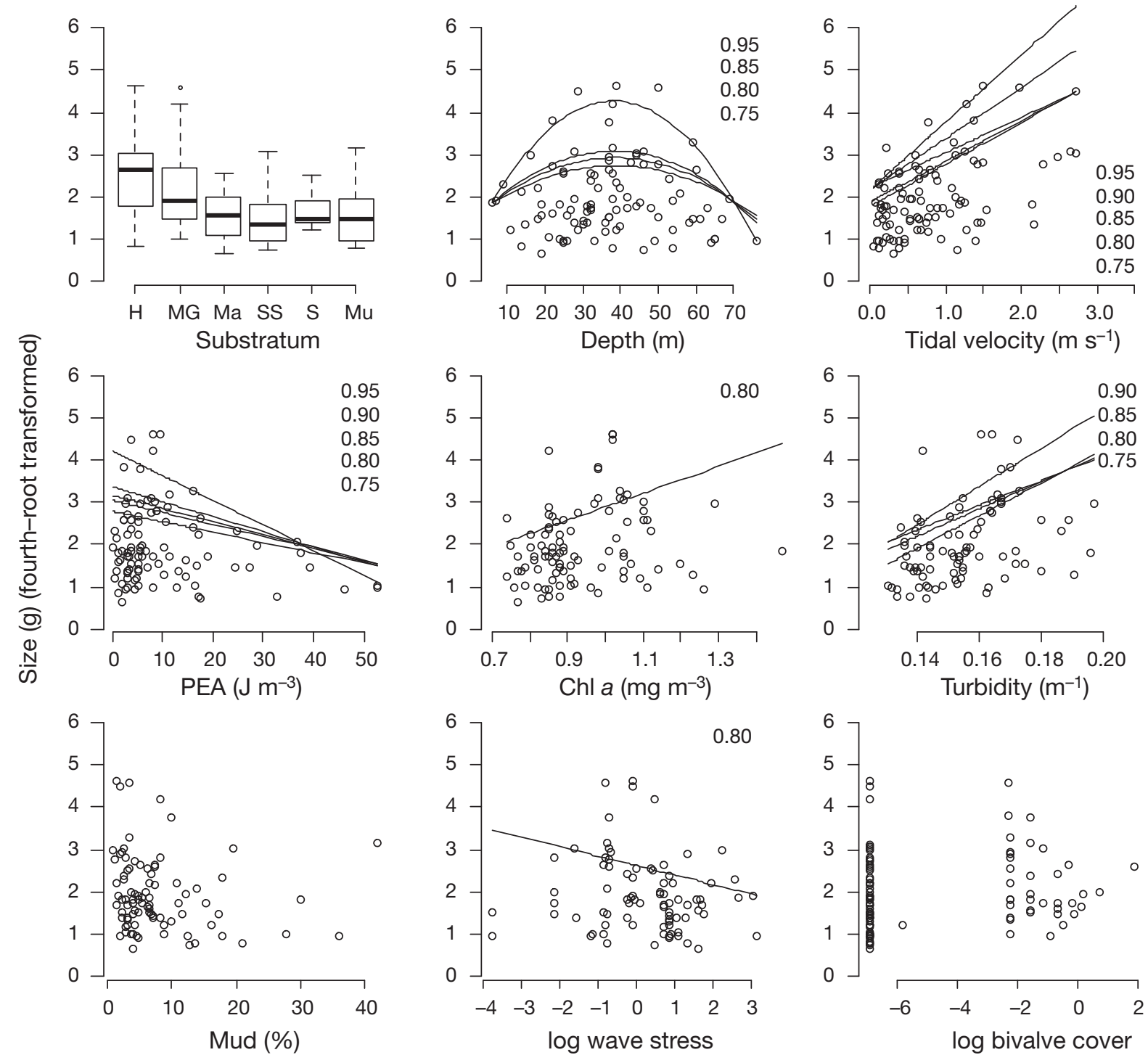

Fig. 3. Maximum size in the overall sessile community in relation to different environmental parameters. Substratum types are hard $(\mathrm{H})$, mixed gravel $(\mathrm{MG})$, maerl (Ma), sand-shell (SS), sand (S), mud (Mu). Size is the fourth-root transformed maximum biomass observed at each station. Black lines are the significant quantile regressions (see Table S4 in the supplement at www.intres.com/articles/suppl/m430p071_supp.pdf for statistics, see also Table 4). Significant quantiles are listed in each panel.

PEA: potential energy anomaly

with and without fishing activities during the year preceding the sampling (Fig. 4). The loss of total biomass due to fishing was estimated between 0 and $34 \%$, with an average of $8 \%$, equivalent to $1.8 \mathrm{~g} \mathrm{~m}^{-2}$, while the decrease in size due to fishing was estimated between 0 and $66 \%$, with an average of $17 \%$.

\section{DISCUSSION}

Scallop dredging changes the size distribution and biomass of sessile epifauna, although the effects were not significant at all taxonomic levels. The effects are demonstrated in the present study at an appropriate scale for the assessment and management of fisheries using an approach that has hitherto been limited to the study of soft sediment communities that are technically simpler to sample (Hiddink et al. 2006). The changes in emergent epifauna with fishing observed here are qualitatively consistent with patterns in other fished areas (Auster et al. 1996, Collie et al. 1997, Thrush et al. 1998, Collie et al. 2000, Bradshaw et al. 2001, Kaiser et al. 2006a), however, our results provide new insights into the magnitude of fishing effects at the scale of an entire fishing fleet, as well as the interaction between the effects of fishing and 
Table 4. Environmental factors limiting the maximum size and total biomasses of the different species groups. Equations and statistics are given in Table S4 in the supplement at www.int-res.com/articles/suppl/m430p071_supp.pdf. See also Fig. 3. + and indicate the response shape of the significant quantile regressions $(+-$ and -+ correspond to convex and concave response curves, respectively). log indicates whether the environmental variable was log-transformed (see Methods for model selection)

\begin{tabular}{|c|c|c|c|c|c|c|c|c|c|}
\hline Species group & Variable & $\begin{array}{l}\text { Depth } \\
\text { (m) }\end{array}$ & $\begin{array}{l}\text { Tidal velocity } \\
\qquad\left(\mathrm{m} \mathrm{s}^{-1}\right)\end{array}$ & $\begin{array}{l}\text { Stratification } \\
\text { PEA }\left(\mathrm{J} \mathrm{m}^{-3}\right)\end{array}$ & $\begin{array}{c}\text { Chl a } \\
\left(\mathrm{mg} \mathrm{m}^{-3}\right)\end{array}$ & $\begin{array}{l}\text { Mud } \\
(\%)\end{array}$ & $\begin{array}{c}\text { Turbidity } \\
\left(\mathrm{m}^{-3}\right)\end{array}$ & $\begin{array}{l}\text { Wave stress } \\
\qquad\left(\mathrm{m} \mathrm{s}^{-2}\right)\end{array}$ & $\begin{array}{c}\text { Bivalve } \\
\text { (\% cover) }\end{array}$ \\
\hline Encrusting & Coverage & & & & & & & & \\
\hline \multirow[t]{2}{*}{ Emergent } & Maximum size & +- & + & - & + & & + & $-\log$ & \\
\hline & Total biomass & +- & $-+\log$ & $-\log$ & $+\log$ & $-\log$ & $+\log$ & $-\log$ & \\
\hline \multirow[t]{2}{*}{ Colonial } & Maximum size & +- & + & & $+\log$ & & $+\log$ & & \\
\hline & Total biomass & +- & $+\log$ & $+-\log$ & $+\log$ & $-\log$ & $+-\log$ & $-\log$ & \\
\hline \multirow[t]{2}{*}{ Solitary } & Maximum size & & $-+\log$ & - & $+\log$ & - & +- & & \\
\hline & Total biomass & & + & - & $+-\log$ & $-\log$ & + & & \\
\hline \multirow[t]{2}{*}{ Hard body } & Maximum size & & $+-\log$ & & & $+\log$ & & $-\log$ & \\
\hline & Total biomass & +- & +- & & & & & & \\
\hline Bivalvia & $\begin{array}{l}\text { Maximum size } \\
\text { Total biomass }\end{array}$ & & $+-\log$ & & & $+\log$ & & $-\log$ & \\
\hline Balanidae & $\begin{array}{l}\text { Maximum size } \\
\text { Total biomass }\end{array}$ & & & & & & & & \\
\hline \multirow[t]{2}{*}{ Flexible } & Maximum size & +- & + & - & + & & $+\log$ & $-\log$ & \\
\hline & Total biomass & +- & $-+\log$ & $-\log$ & $+\log$ & $-\log$ & $+\log$ & $-\log$ & \\
\hline \multirow[t]{2}{*}{ Cnidaria } & Maximum size & & + & - & + & & $+\log$ & $-\log$ & \\
\hline & Total biomass & +- & $+\log$ & - & $+\log$ & $-\log$ & $+\log$ & $-\log$ & \\
\hline \multirow[t]{2}{*}{ Hydrozoa } & Maximum size & & $-+\log$ & & $+\log$ & & $+\log$ & & \\
\hline & Total biomass & - & $-+\log$ & - & $+\log$ & $-\log$ & +- & & \\
\hline \multirow[t]{2}{*}{ Anthozoa } & Maximum size & +- & $+\log$ & $+-\log$ & & & $+{ }_{\log }$ & $-\log$ & \\
\hline & Total biomass & +- & + & - & $+\log$ & - & + & $-\log$ & \\
\hline \multirow[t]{2}{*}{ Bryozoa } & Maximum size & & + & - & & & & & \\
\hline & Total biomass & - & + & - & $-\log$ & & & & \\
\hline \multirow[t]{2}{*}{ Porifera } & Maximum size & & - & & & & & & $-+\log$ \\
\hline & Total biomass & & +- & - & & -+ & & & $-+\log$ \\
\hline \multirow[t]{2}{*}{ Ascidiacea } & Maximum size & - & & -+ & & $-\log$ & & & \\
\hline & Total biomass & - & & $-\log$ & & $-\log$ & & & \\
\hline
\end{tabular}

Table 5. Results of the Moran's $I$ and Geary's $C$ spatial autocorrelation tests

\begin{tabular}{|lccc|}
\hline $\begin{array}{c}\text { Area } \\
\text { Species group }\end{array}$ & Moran's $I$ & $\begin{array}{c}\text { Moran's } I \\
\text { p-value }\end{array}$ & $\begin{array}{c}\text { Geary's } C \\
\text { p-value }\end{array}$ \\
\hline East & & & \\
Bivalvia & 0.007 & 0.212 & 0.704 \\
Balanidae & 0.005 & 0.096 & 0.156 \\
Hydrozoa & 0.034 & 0.01 & 0.169 \\
Anthozoa & 0.01 & 0.171 & 0.042 \\
Bryozoa & 0.035 & 0.005 & 0.031 \\
Porifera & 0.077 & $<0.001$ & $<0.001$ \\
Ascidiacea & 0.017 & 0.09 & 0.89 \\
West & & & \\
Bivalvia & 0.027 & 0.018 & 0.416 \\
Balanidae & -0.004 & 0.116 & 0.893 \\
Hydrozoa & 0.128 & $<0.001$ & $<0.001$ \\
Anthozoa & 0.068 & $<0.001$ & $<0.001$ \\
Bryozoa & -0.013 & 0.825 & 0.903 \\
Porifera & 0.081 & $<0.001$ & $<0.001$ \\
Ascidiacea & 0.037 & 0.005 & 0.208 \\
\hline
\end{tabular}

the environment. The final estimate of biomass loss due to fishing has to be interpreted with caution, however, as most organisms had very flexible struc-
Table 6. Variable importance in projection for each original variable in latent variables 1 and 2 (LV1 and LV2) for both maximum size and total biomass of habitat-forming organisms in hard-bottom areas

\begin{tabular}{|lcccc|}
\hline & \multicolumn{2}{c|}{ Maximum size } & \multicolumn{2}{c|}{ Total biomass } \\
& Comp1 & Comp2 & Comp1 & Comp2 \\
\hline Fishing frequency & 1.40 & 1.45 & 0.95 & 1.16 \\
Tidal velocity & 1.28 & 1.30 & 1.39 & 1.34 \\
Wave stress & 1.17 & 1.07 & 1.46 & 1.34 \\
Chl a & 0.14 & 0.18 & 0.17 & 0.21 \\
Turbidity & 0.01 & 0.02 & 0.01 & 0.03 \\
\hline
\end{tabular}

tures that impaired some estimates of coverage or biomass based on photographic methods.

Studies of fishing impacts are usually based on experimental manipulations of fishing intensity, comparisons of fished and unfished areas, or trends in time series (Eleftheriou \& Robertson 1992, Thrush et al. 1995, Auster et al. 1996, Hill et al. 1999, Kaiser et al. 2006a). These studies have sought to reduce variability due to the environment within the experimental design to focus on fishing effects. Conversely, we sought to assess fishing impacts at a large and fishery- 


\section{Without fishing effort}

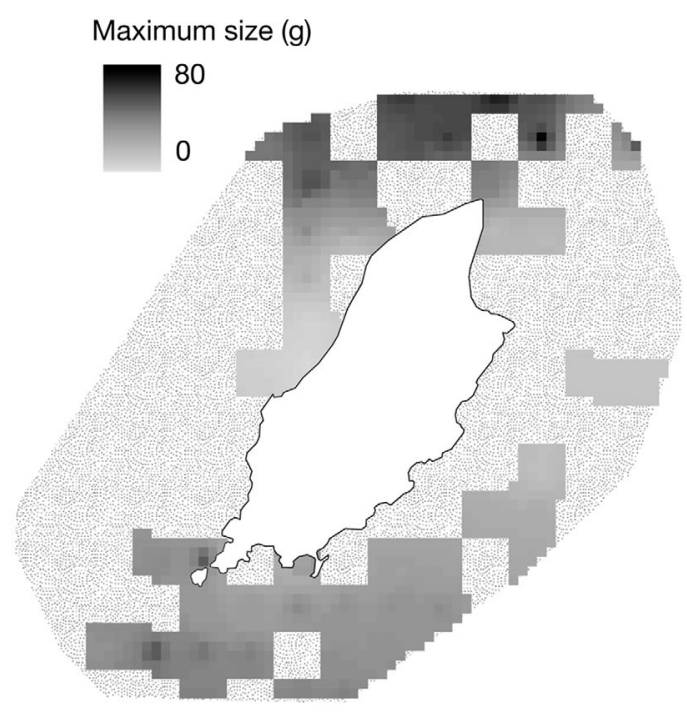

Total biomass $\left(\mathrm{g} \mathrm{m}^{-2}\right)$

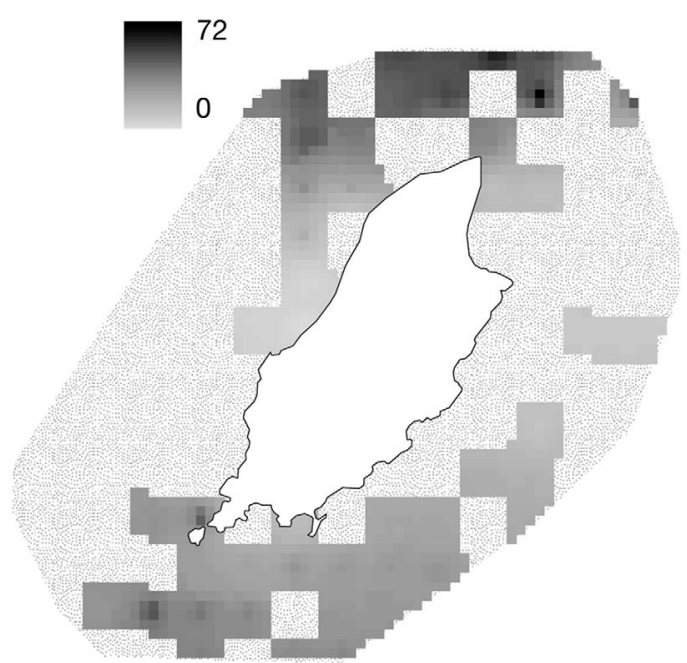

With fishing effort

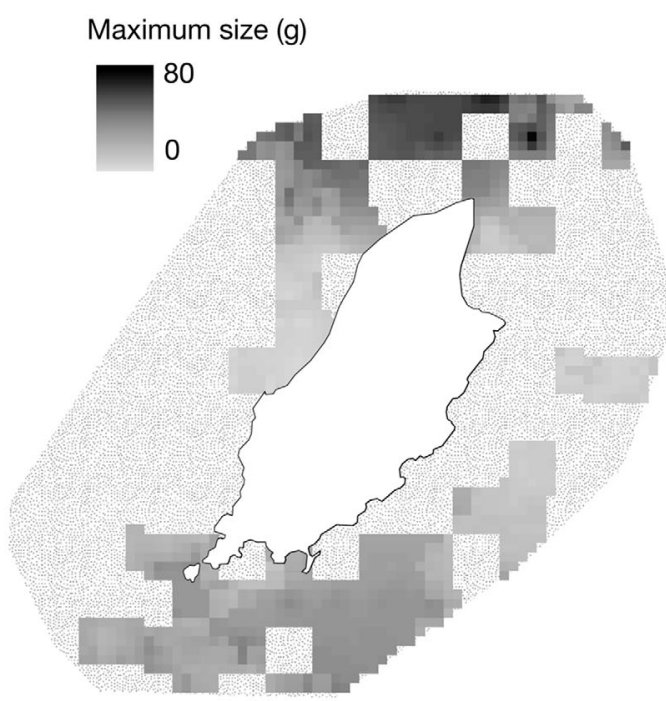

Total biomass $\left(\mathrm{g} \mathrm{m}^{-2}\right)$

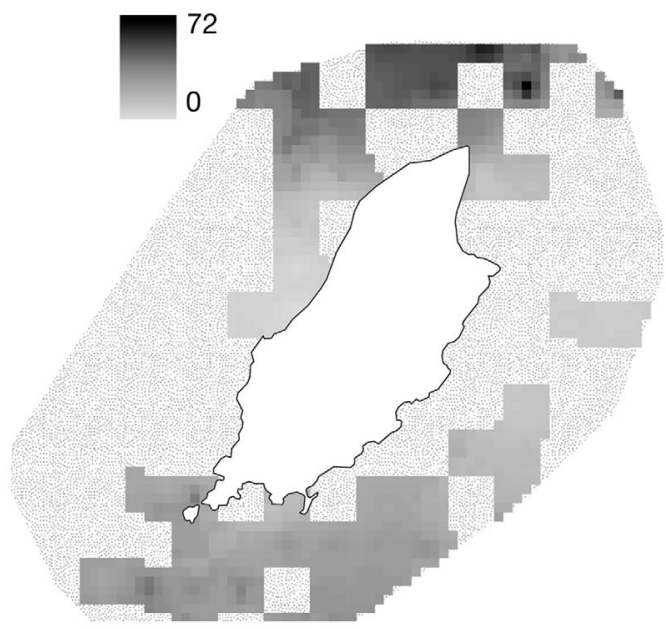

Fig. 4. Predictive maps of potential maximum size (top) and total biomass (bottom) of sessile epifauna in hard substratum areas based on hydrodynamic conditions without (left) and with (right) fishing effort. The dotted area represents unstable substratum types

relevant scale while taking account of the environmental variation that was present.

Our results showed that the distribution of habitatforming species was not only dependent on the fishing frequency but also on the availability of hard substratum, tidal velocity and wave stress. At the scale of our study, chl a and turbidity did not explain the observed distribution of the epifauna. Hard substratum provides an opportunity for these fauna to settle and develop. The responses of the epifauna to wave stress and tidal velocity were mostly monotonic, which may have been due to the range covered by the gradients and to the lack of data in the extreme values of the gradients. Stronger tidal currents were generally associated with a higher biomass of emergent epifauna, consistent with the dependence of production on water flow that influences feeding efficiency, colony morphology and patch size (Wildish et al. 1997, Coma et al. 1998, Rees et al. 1999). Increasing wave stress was associated with a decrease in the biomass and maximum size of the emergent epifauna, consistent with the recognition that it can be a source of mortality in benthic communities (Emerson 1989). Wave-induced mortality is known to impact community structure to a water depth of approximately $50 \mathrm{~m}$ on continental shelves (Oliver et al. 1980, Hall 1994, 
Hiddink et al. 2006), but below $50 \mathrm{~m}$ it is unlikely that wave erosion will dislocate or damage organisms that are anchored to the seabed or substratum (Wildish et al. 1997). Our study revealed peak biomass and body sizes at intermediate depth, which may correspond to an area of where there is an optimum trade-off between tidal currents and wave stress (see also Kaiser et al. 2006b).

The analysis of taxon-specific responses to fishing and the environment was informative about more complex interactions in the epifaunal communities. Although spatial autocorrelations might have influenced the significance of the responses, sponges were the only taxon limited by the percentage cover of bivalves, which reflected the affinity of sponges for Modiolus beds and their colonisation of living queen scallop shells. The total biomass and maximum size of sponges and bivalves both decreased at the highest tidal velocities, which may reflect their larval settlement abilities or their feeding modes. The efficiency of passive suspension feeding tends to rely upon the flux of seston, while active suspension feeding is most likely determined by seston concentration (Lesser 2006). Bivalves, barnacles and most sponges are active suspension feeders while hydroids and anthozoans are mostly passive feeders (Labarbera 1984, Okamura 1987, Wildish et al. 1997, Coma et al. 1998). Colony morphology may also have an important influence on feeding success since it influences the relationship between flow and prey-capture success (Sebens \& Johnson 1991, Coma et al. 1998). The complex upright structure of some passive emergent epifauna might induce a higher efficiency in particle capture at higher flow regimes than their smaller active suspension feeder counterparts, such as the sponges observed at the studied sites.

The community studied herein was similar to the cobble community described by Henry et al. (2006) on the Western Bank, northwest Atlantic, being dominated by hydroids such as Hydrallmania falcata, Abietinaria abietina and Halecium halecinum, as well as the anthozoan Alcyonium digitatum, bryozoan Cellaria sinuosa and tunicate Ascidia spp. However, Henry et al. (2006) reported that the biomass of these habitat-forming species was not affected by fishing. This apparent contradiction can be explained because Henry et al. (2006) studied the impact of a single pass of an otter trawl, whereas repeated scallop dredging over longer time periods in a real fishery will have greater impacts on benthic habitats and fauna (e.g. Collie et al. 2000).

Reductions in the biomass of epifauna reduce habitat complexity (Cranfield et al. 2004, Sanderson et al. 2008). The present study further suggests that not only the overall biomass decreases, but also the size distribution moves towards small body-sized organisms, and although not the primary focus of the present study, this loss in complexity is expected to affect other species such as mobile epifauna or juvenile fish that rely on the shelter or food that habitat heterogeneity provides (Auster et al. 1996, Bradshaw et al. 2003, Scharf et al. 2006). Because of the loss in biomass of sessile organisms due to fishing, the fishery may also have a direct impact on the recruitment of scallops if it reduces habitat to an extent that habitat availability becomes limiting, as scallop spat have been observed to settle on emergent species such as the bryozoans Cellaria sinuosa (Fig. 5, Paul 1981, G. I. Lambert and H. Hinz pers. obs.). Further research on the degree of specialisation of the associations between scallop spat and sessile organisms would be very relevant to fisheries management in light of the findings of the present study.

Encrusting species may benefit from the removal of erect species that compete for space and food (Collie et al. 2000, Bradshaw et al. 2001). In our study, the group of encrusting species, consisting of unidentified 2-dimensional bryozoans and sponges, did not show

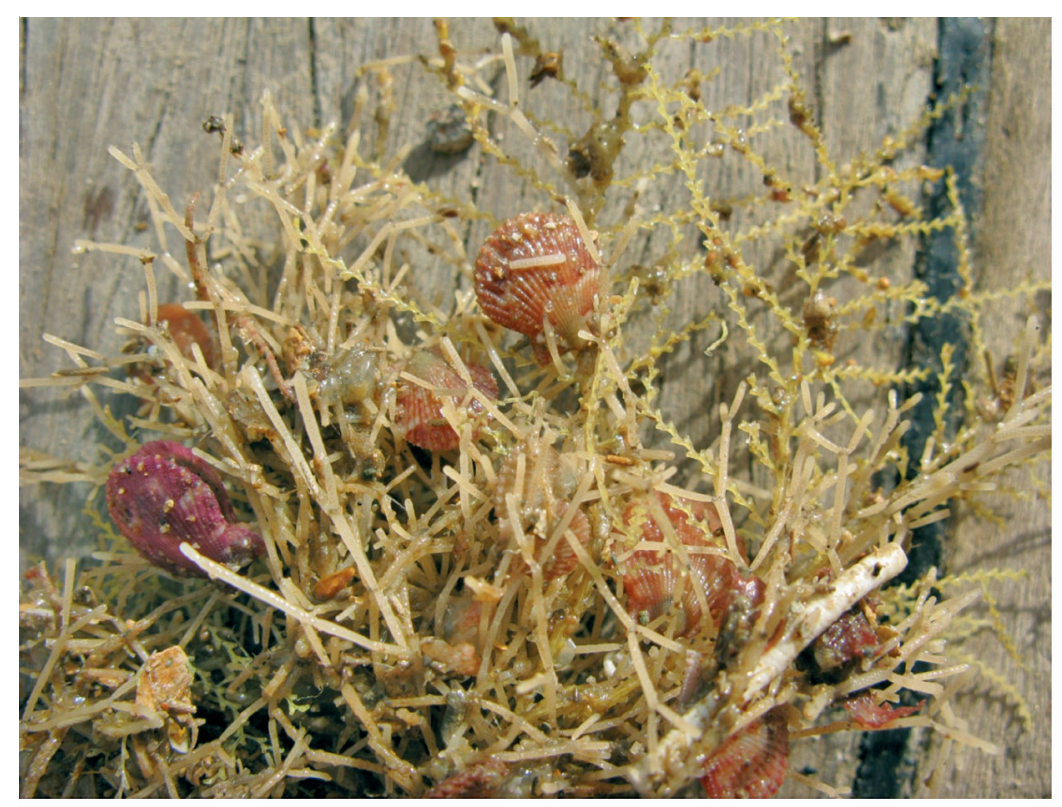

Fig. 5. Settlement of Aequipecten opercularis spat on the complex sessile turf of bryozoa Cellaria sinuosa and hydroid Sertularella gayi, illustrating the role of emergent epifauna as a settlement substrate for scallops. Sample collected by a scallop dredge during the October 2009 survey in the Isle of Man waters (Photograph @ Hilmar Hinz) 
any response to fishing disturbance. Identifiable sponges, however, showed a positive response to fishing intensity. Although these were categorised as emergent epifauna, most species are mound shaped and encrusting (e.g. Myxilla incrustans or Hemimycale columella), and, thus, the increase in biomass may be a response to the removal of other, more upright, epifauna. Additionally, sponges are known to be able to adapt their body form in response to physical environmental conditions (Bell \& Barnes 2000). If the sponge species observed in our study are able to adapt their body form to a less vulnerable encrusting morphology, they may benefit from the impact of fishing on the competing epifauna.

Quantile and PLS regressions are rarely adopted in studies of human and environmental impacts (see Vaz et al. 2008, Carrascal et al. 2009 for further details), but, in the present study, were valuable tools to reveal relationships in a dataset with multiple interacting environmental factors. Quantile regressions can handle zero-inflated datasets (Vaz et al. 2008), which was useful when studying variation in rare taxonomic groups. As with other linear regression methods, these approaches can provide misleading results if the numbers of observations are not evenly distributed along fishing or environmental gradients, and they have been criticised for describing potential rather than realised patterns (Vaz et al. 2008). The use of PLS regressions was intended to eliminate these limitations while dealing with the problem of co-linearity among predictors. The outcome of the PLS regression was significant for the hard-bottom areas, and consistent with the responses identified by the quantile regressions. Additional tests of the predictive model will require further data collection in areas with comparable environmental conditions.

We have shown that it is possible to quantify and model the biomass and size distribution of emergent habitat-forming species. The main model predictors were hard substratum availability, fishing frequency and hydrodynamics knowledge. These habitats have previously been under-represented in studies designed to quantify the impact of fishing activities on seabed biota, as these communities are problematic and time-consuming to sample in a quantitative and repeatable way. The communities associated with hard substrata are of conservational importance, as they tend to be dominated by epifaunal turfs that have high levels of associated diversity and that provide a source of prey and shelter to species of commercial importance. Including only natural factors in the model, it was possible to predict the potential distribution of these habitats and thus to identify areas that were potentially sensitive to fishing impacts from areas where, despite the absence of fishing, sessile species were not likely to develop (Fig. 4). Based on our model, we limited the mapping to the distribution of sessile epifauna on hard substrata. Further research would be necessary to provide a complete map of habitat sensitivity as all soft substratum areas (dotted grey area on the maps, Fig. 4), were not modelled. In these areas, anemones, Modiolus, maerl beds and special bed forms have been observed. Our study provides an important step towards being able to quantify the loss in ecosystem services associated with sessile fauna in relation to fishing frequency, such that it will be possible to formulate management strategies to assess the sustainability and mitigation of such effects.

Acknowledgements. The authors thank the UK Department of Environment, Food and Rural Affairs (Project M1001) for funding this research. We are grateful to the Isle of Man Ministry of Fisheries for permission to use the data and photographs from their habitat mapping survey conducted in August 2008 and NEODASS for allowing the use of the satellite monitoring data. We also thank L. Murray for his help with obtaining the VMS data and numerous Bangor University students for their participation at different stages of the project.

\section{LITERATURE CITED}

Auster PJ, Malatesta RJ, Langton RW, Watling L (1996) The impacts of mobile fishing gear on seafloor habitats in the Gulf of Maine: implications for conservation of fish populations. Rev Fish Sci 4:185-202

Bell JJ, Barnes DKA (2000) The influences of bathymetry and flow regime upon the morphology of sublittoral sponge communities. J Mar Biol Assoc UK 80:707-718

Blackburn TM, Lawton JH, Perry J (1992) A method for estimating the slope of upper bounds in plots of body size and abundance in natural animal assemblages. Oikos 65: 107-112

Bradshaw C, Veale LO, Hill AS, Brand AR (2001) The effect of scallop dredging on Irish Sea benthos: experiments using a closed area. Hydrobiologia 465:129-138

Bradshaw C, Collins P, Brand AR (2003) To what extent does upright sessile epifauna affect benthic biodiversity and community composition? Mar Biol 143:783-791

> Cade BS, Noon BR (2003) A gentle introduction to quantile regression for ecologists. Front Ecol Environ 1:412-420

> Cade BS, Terrell JW, Schroeder RL (1999) Estimating effects of limiting factors with regression quantiles. Ecology 80: 311-323

Callaway R, Alsvag J, de Boois I, Cotter J and others (2002) Diversity and community structure of epibenthic invertebrates and fish in the North Sea. ICES J Mar Sci 59: $1199-1214$

Carrascal LM, Galvan I, Gordo O (2009) Partial least squares regression as an alternative to current regression methods used in ecology. Oikos 118:681-690

Chong IG, Jun CH (2005) Performance of some variable selection methods when multicollinearity is present. Chemom Intell Lab Syst 78:103-112

> Collie JS, Escanero GA, Valentine PC (1997) Effects of bottom fishing on the benthic megafauna of Georges Bank. Mar Ecol Prog Ser 155:159-172 
Collie JS, Escanero GA, Valentine PC (2000) Photographic evaluation of the impacts of bottom fishing on benthic epifauna. ICES J Mar Sci 57:987-1001

Coma R, Ribes M, Zabala M, Gili JM (1998) Growth in a modular colonial marine invertebrate. Estuar Coast Shelf Sci 47:459-470

> Cranfield HJ, Rowden AA, Smith DJ, Gordon DP, Michael KP (2004) Macrofaunal assemblages of benthic habitat of different complexity and the proposition of a model of biogenic reef habitat regeneration in Foveaux Strait, New Zealand. J Sea Res 52:109-125

Cushman SA, McGariyal K, Neel MC (2008) Parsimony in landscape metrics: Strength, universality, and consistency. Ecol Indic 8:691-703

Eleftheriou A, Moore DC (2005) Macrofauna techniques. In: Eleftheriou A, McIntyre A (eds) Methods for the study of Marine Benthos. Blackwell Science, Oxford, p 160-228

Eleftheriou A, Robertson MR (1992) The effects of experimental scallop dredging on the fauna and physicalenvironment of a shallow sandy community. Neth J Sea Res 30:289-299

Emerson CW (1989) Wind stress limitation of benthic secondary production in shallow, soft-sediment communities. Mar Ecol Prog Ser 53:65-77

FAO (2003) Fisheries management 2. The ecosystem approach to fisheries. FAO Technical Guidelines for Responsible Fisheries Vol 4, Suppl 2, FAO, Rome

Gili JM, Hughes RG (1995) The ecology of marine benthic hydroids. Oceanogr Mar Biol Annu Rev 33:351-426

Hall SJ (1994) Physical disturbance and marine benthic communities: life in unconsolidated sediments. Oceanogr Mar Biol Annu Rev 32:179-239

Henry LA, Kenchington ELR, Kenchington TJ, MacIsaac KG, Bourbonnais-Boyce C, Gordon DC (2006) Impacts of otter trawling on colonial epifaunal assemblages on a cobble bottom ecosystem on Western Bank (northwest Atlantic). Mar Ecol Prog Ser 306:63-78

Hiddink JG, Jennings S, Kaiser MJ, Queirós AM, Duplisea DE, Piet GJ (2006) Cumulative impacts of seabed trawl disturbance on benthic biomass, production and species richness in different habitats. Can J Fish Aquat Sci 63: 721-736

Hiddink JG, Jennings S, Kaiser MJ (2007) Assessing and predicting the relative ecological costs of disturbance to habitats with different sensitivities. J Appl Ecol 44:405-413

Hiddink JG, Davies TW, Perkins M, Machairopoulou M, Neill SP (2009) Context dependency of relationships between biodiversity and ecosystem functioning is different for multiple ecosystem functions. Oikos 118:1892-1900

Hill AS, Veale LO, Pennington D, Whyte SG, Brand AR, Hartnoll RG (1999) Changes in Irish Sea benthos: possible effects of 40 years of dredging. Estuar Coast Shelf Sci 48:739-750

Jenkins SR, Beukers-Stewart BD, Brand AR (2001) Impact of scallop dredging on benthic megafauna: a comparison of damage levels in captured and non-captured organisms. Mar Ecol Prog Ser 215:297-301

> Jennings S, Lancaster J, Woolmer A, Cotter J (1999) Distribution, diversity and abundance of epibenthic fauna in the North Sea. J Mar Biol Assoc UK 79:385-399

> Jennings S, Dinmore TA, Duplisea DE, Warr KJ, Lancaster JE (2001) Trawling disturbance can modify benthic production processes. J Anim Ecol 70:459-475

> Jumars PA, Thistle D, Jones ML (1977) Detecting twodimensional spatial structure in biological data. Oecologia 28:109-123

Kaiser MJ (2005) Are Marine Protected Areas a red herring or fisheries panacea? Can J Fish Aquat Sci 62:1194-1199
Kaiser MJ, Cheney K, Spence FE, Edwards DB, Radford K (1999) Fishing effects in northeast Atlantic shelf seas: patterns in fishing effort, diversity and community structure VII. The effects of trawling disturbance on the fauna associated with the tubeheads of serpulid worms. Fish Res 40:195-205

Kaiser MJ, Collie JS, Hall SJ, Jennings S, Poiner IR (2002) Modification of marine habitats by trawling activities: prognosis and solutions. Fish Fish 3:114-136

Kaiser MJ, Clarke KR, Hinz H, Austen MCV, Somerfield PJ, Karakassis I (2006a) Global analysis and prediction of the response of benthic biota to fishing. Mar Ecol Prog Ser 311:1-14

- Kaiser MJ, Galanidi M, Showler DA, Elliott AJ and others (2006b) Distribution and behaviour of common scoter Melanitta nigra relative to prey resources and environmental parameters. Ibis 148:110-128

Kendall MS, Jensen OP, Alexander C, Field D, McFall G, Bohne R, Monaco ME (2005) Benthic mapping using sonar, video transects, and an innovative approach to accuracy assessment: a characterization of bottom features in the Georgia Bight. J Coast Res 21:1154-1165

> Koenker R, Bassett G (1978) Regression quantiles. Econometrica 46:33-50

Kraan C, van der Meer J, Dekinga A, Piersma T (2009) Patchiness of macrobenthic invertebrates in homogenized intertidal habitats: hidden spatial structure at a landscape scale. Mar Ecol Prog Ser 383:211-224

Labarbera M (1984) Feeding currents and particle capture mechanisms in suspension feeding animals. Am Zool 24: 71-84

> Lesser MP (2006) Benthic-pelagic coupling on coral reefs: Feeding and growth of Caribbean sponges. J Exp Mar Biol Ecol 328:277-288

Mevik BH, Wehrens R (2007) The pls package: principal component and partial least squares regression in R. J Stat Softw 18(2)

Okamura B (1987) Particle-size and flow velocity induce an inferred switch in bryozoan suspension-feeding behavior. Biol Bull 173:222-229

Oliver JS, Slattery PN, Hulberg LW, Nybakken JW (1980) Relationships between wave disturbance and zonation of benthic invertebrate communities along a subtidal high-energy beach in Monterey Bay, California. Fish Bull 78: 437-454

Paul JD (1981) Natural settlement and early growth of spat of the queen scallop Chlamys Opercularis (L), with reference to the formation of the 1st growth ring. J Molluscan Stud 47:53-58

Rees HL, Pendle MA, Waldcock R, Limpenny DS, Boyd SE (1999) A comparison of benthic biodiversity in the North Sea, English Channel, and Celtic Seas. ICES J Mar Sci 56:228-246

Rossi JP, van Halder I (2010) Towards indicators of butterfly biodiversity based on a multiscale landscape description. Ecol Indic 10:452-458

> Sanderson WG, Holt RHF, Kay L, Ramsay K, Perrins J, McMath AJ, Rees EIS (2008) Small-scale variation within a Modiolus modiolus (Mollusca: Bivalvia) reef in the Irish Sea. II. Epifauna recorded by divers and cameras. J Mar Biol Assoc UK 88:143-149

> Scharf FS, Manderson JP, Fabrizio MC (2006) The effects of seafloor habitat complexity on survival of juvenile fishes: Species-specific interactions with structural refuge. J Exp Mar Biol Ecol 335:167-176

> Sebens KP, Johnson AS (1991) Effects of water-movement on prey capture and distribution of reef corals. Hydrobiologia 226:91-101 
Simpson JH, Tett PB, Argoteespinoza ML, Edwards A, Jones KJ, Savidge G (1982) Mixing and phytoplankton growth around an island in a stratified sea. Cont Shelf Res 1:15-31

Sinclair M, Valdimarsson G (2003) Responsible fisheries in the marine ecosystem. CABI publishing, Cambridge MA

Thrush SF, Hewitt JE, Cummings VJ, Dayton PK (1995) The impact of habitat disturbance by scallop dredging on marine benthic communities: What can be predicted from the results of experiments? Mar Ecol Prog Ser 129: 141-150

Thrush SF, Hewitt JE, Cummings VJ, Dayton PK and others (1998) Disturbance of the marine benthic habitat by commercial fishing: impacts at the scale of the fishery. Ecol Appl 8:866-879

Van Dolah RF, Wendt PH, Nicholson N (1987) Effects of a

Editorial responsibility: Richard Osman,

Edgewater, Maryland, USA research trawl on a hard-bottom assemblage of sponges and corals. Fish Res 5:39-54

Vaz S, Martin CS, Eastwood PD, Ernande B, Carpentier A, Meaden GJ, Coppin F (2008) Modelling species distributions using regression quantiles. J Appl Ecol 45:204-217

Venables WN, Ripley BD (2002) Modern applied statistics with $S$, Springer, Berlin

Wildish D, Kristmanson D (1997) Benthic suspension feeders and flow. Cambridge University Press, Cambridge

Wold S, Sjostrom M, Eriksson L (2001) PLS-regression: a basic tool of chemometrics. Chemom Intell Lab Syst 58:109-130

Zhang YX, Richardson JS, Pinto X (2009) Catchment-scale effects of forestry practices on benthic invertebrate communities in Pacific coastal streams. J Appl Ecol 46: 1292-1303

Submitted: November 10, 2010; Accepted: February 27, 2011 Proofs received from author(s): May 10, 2011 